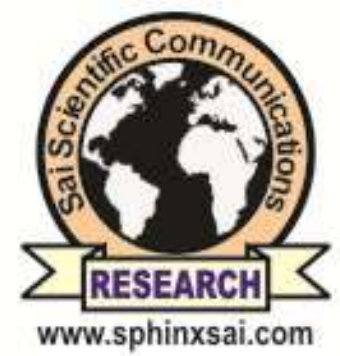

Phardinteren

International Journal of PharmTech Research CODEN (USA): IJPRIF, ISSN: 0974-4304, ISSN(Online): 2455-9563

Vol.10, No.4, pp 237-245,

2017

\title{
Apoptosis Inducing Factor (AIF) Stabilizes Menadione- Conjugate Product in Programmed Cell Death
}

\author{
Hesti L. Wiraswati ${ }^{1,3}$, Muhamad A. Martoprawiro ${ }^{1,2}$, \\ Akhmaloka $^{1}$, Fida M. Warganegara ${ }^{1 *}$ \\ 'Department of Chemistry, Institut Teknologi Bandung, Jl. Ganeca 10, Bandung 40132, \\ Indonesia \\ ${ }^{2}$ Department of Computational Sciences, Institut Teknologi Bandung, Jl. Ganeca 10, \\ Bandung 40132, Indonesia \\ ${ }^{3}$ Université Paris Sud, Paris-Cedex, France
}

\begin{abstract}
Understanding the role of AIF modulate menadione cytotoxicity may lead Apoptosis Inducing Factor (AIF) contribution as potential target of cancer drugs. Previous studies reported the impact of mitochondrial AIF to cytotoxicity of menadione (2-methyl-1,4naphtoquinone). Specifically, recent study revealed that AIF depletion reduced the level of thiodione (arylation product of menadione and reduced gluthatione, GSH) and increased endogenous GSH. However, how AIF modulate menadione-GSH arylation, has not been elaborated yet. This study investigated the involvement of AIF to arylation capacity of menadione using in silico approach. Molecular interaction between residues on AIF and functional groups of menadione were investigated using AutoDockVina software. The result confirmed that AIF is involved in the conjugation of menadione and GSH to form thiodione. AIF also tends to stabilize thiodione formation rather than interact with menadione or GSH directly. Moreover, AIF doesn't show transferase catalytic site which reinforce the notion that AIF stabilizes conjugate product-thiodione.
\end{abstract}

Keywords : AIF, menadione, apoptosis, docking.

\section{Introduction}

Apoptosis Inducing Factor (AIF) is mitochondrial protein that play a role in programmed cell death in caspase-independent manner. Several studies reported that certain cancer drugs impact to AIF response. Those drugs exhibit toxic effect in association with oxidative stress. One of them is menadione (2-methyl-1,4naphtoquinone; vitamine K3), a drug belonging to the quinone family at elevated concentrations is studied for its anti-cancer potential. Clinically, menadione belong to the group of drugs from the class of quinones which in high concentrations studied for potential anti-cancer. Pharmacologically, menadione importantly was used as a chemotherapeutic agent in diseases such as leukemia and gastrointestinal cancer ${ }^{1,2,3}$.

International Journal of PharmTech Research, Vol.10, No.4, pp 237-245, (2017)

http://dx.doi.org/10.20902/IJPTR.2017.10430 
Two capacities of menadione are considered to be responsible for its lethal action; First, redox cycle associated with ROS production. Second, arylation capacity to form conjugation product with cysteine functional group of key proteins in the cell. Rapid redox cycling of menadione is associated with its ability to do one-electron to form semiquinone radicals and two-electron reduction to form hydroquinone that less toxic than semiquinone radical. In addition of its lethal formations, menadione can bind to thiols protein in the cell, caused a decline in the levels of antioxidants in the cells ${ }^{4,5,6}$. One event detected in the experiment is the fluorescent product between menadione and antioxidant GSH, which is known as the 'thiodione ${ }^{17,6}$.

Several studies reported that menadione is associated to the response of mitochondrial Apoptosis Inducing Factor $(\mathrm{AIF})^{8,9,10,11}$.Moreover, biophysical studies revealed that menadione could easily enter the mitochondrial membrane ${ }^{12}$ and it does not cause disruption of mitochondrial membrane potential ${ }^{13}$, this situation allow menadione to interact with mitochondrial proteins such as AIF. This is in agreement with recent study that revealed the link of menadione cytotoxicity and AIF without causing the lost of mitochondrial membrane potential and kept the AIF inside the mitochondria during its action ${ }^{11}$. The response of AIF to menadione induction, suggests that the lethal action of AIF connects with both cytotoxic mechanisms of menadione. Many reports revealed reductase activity of $\mathrm{AIF}^{8,14,15,10,9}$ and subsequent studies linked this activity to menadione cytotoxicity ${ }^{9,16}$. While, lethal action of AIF in the modulation of thiodione formation is rarely studied. Recent study revealed that AIF modulate arylation capacity of menadione in cancer cell model ${ }^{11}$. The study revealed that AIF depletion reduced the level of thiodione (arylation product of menadione and reduced gluthatione) and increased endogenous reduced gluthatione ${ }^{11}$. However, how molecular interaction of AIF in the presence of menadione has not been elaborated yet. Study the role of AIF in menadione cytotoxicity is important for finding new target therapy targeting AIF. As well as its survival activity, the lethal action of AIF could not be separated of its 3D structure. For instance, murine AIF has several domains; FAD (aa 122-262 and aa 400-477) and NADH (aa 263-399) binding domain associated with oxidoreductase activity for cell survival ${ }^{14}$, C-terminal domain (aa 478-610) which is considered as pro-apoptotic domain ${ }^{14,15}$, and N-terminal domain which is used to anchor in mitochondria ${ }^{17}$. This research was designed to know the interaction mode between AIF and some ligands, which is important in oncology field especially to the development of cancer resistance and could contribute for finding a new cancer therapies targeting AIF.This study focus on the investigation of molecular interaction between functional groups of compounds which is involved in menadionearylation and residues of AIF using computational approaches.

Table 1. Receptors and ligands used in this study

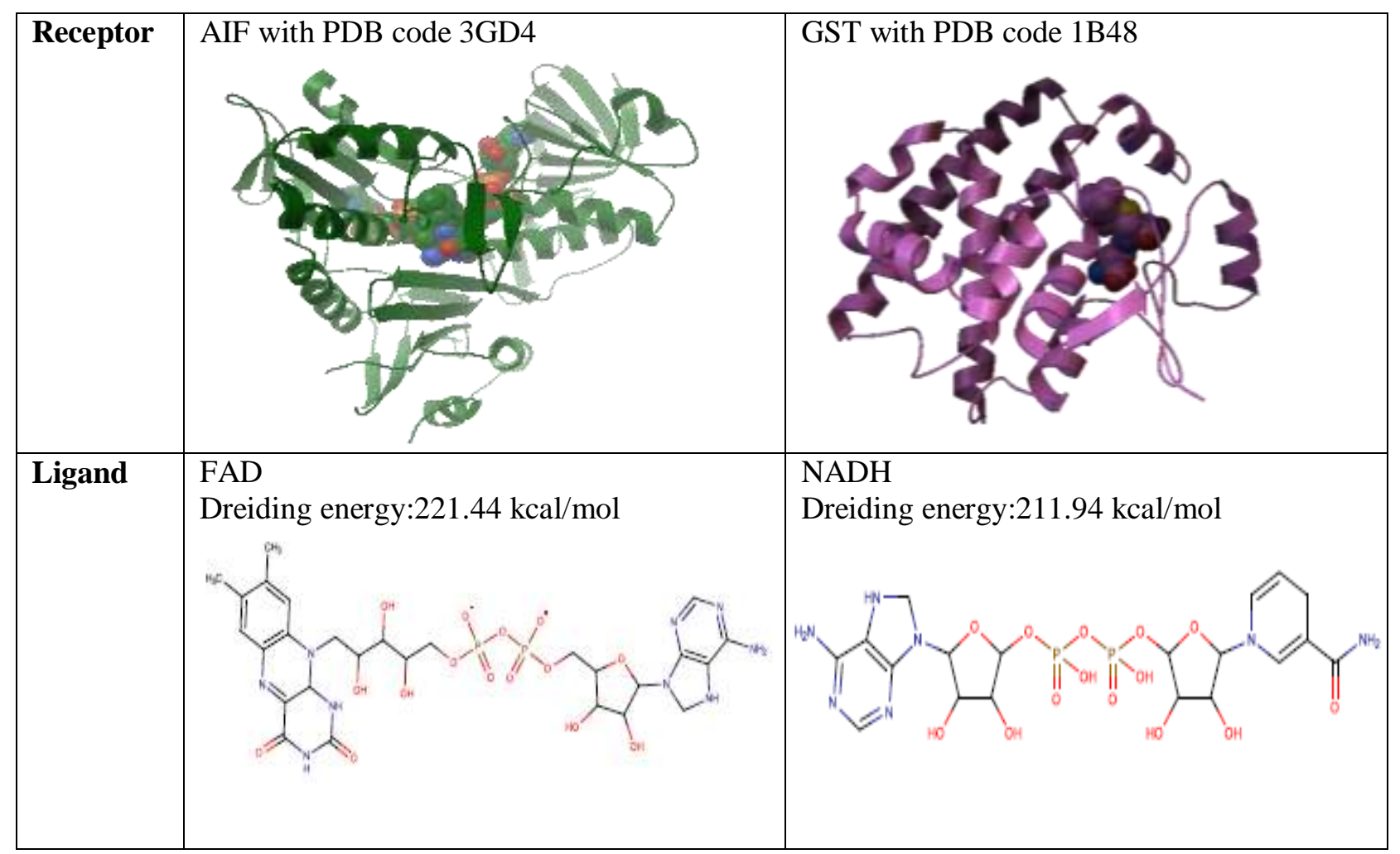




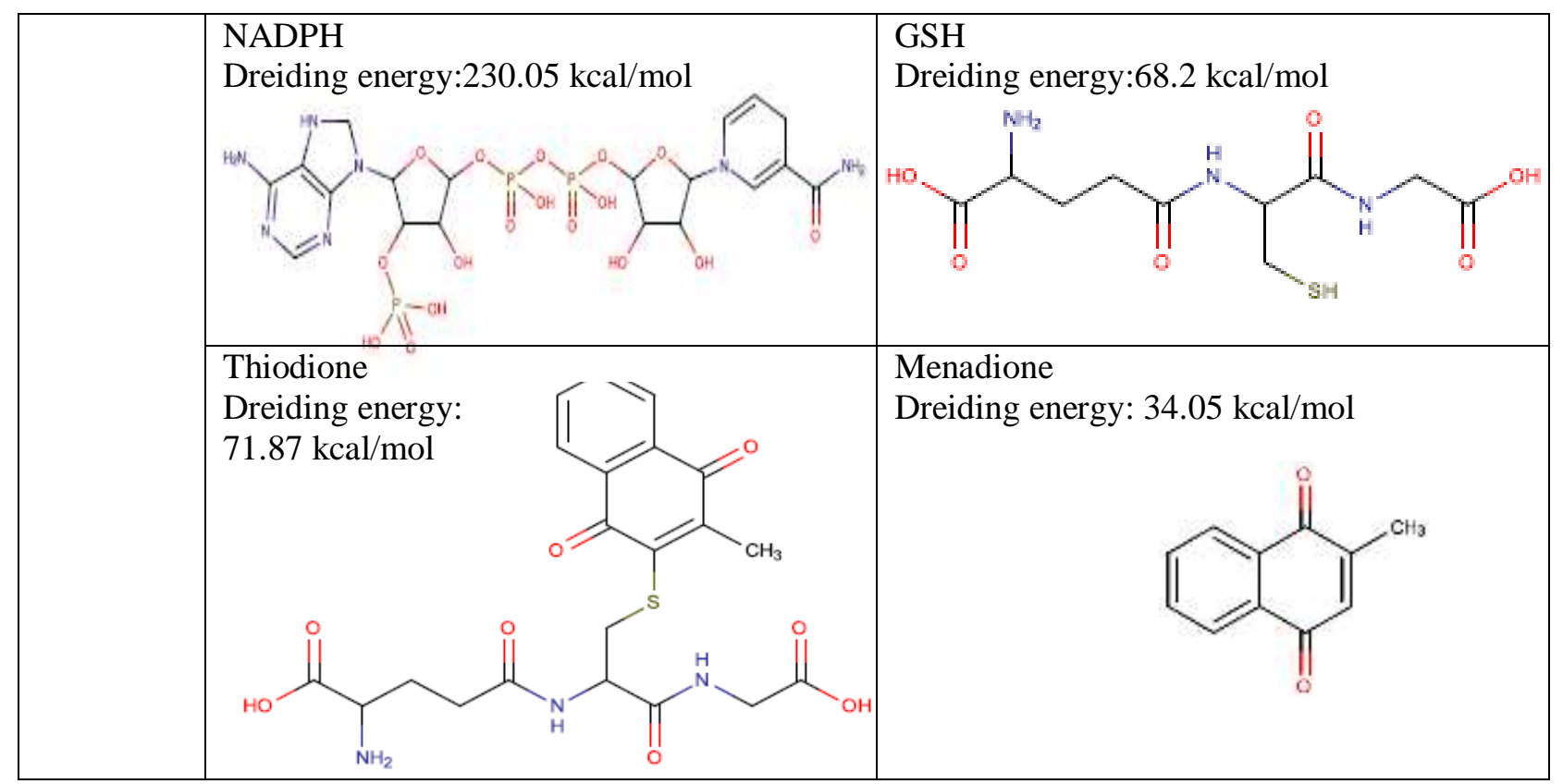

\section{Experimental}

\section{Protein and ligands preparation for computational study.}

The crystal structure of Apoptosis Inducing Factor (AIF) and gluthatione-S-transferase (GST) with PDB code subsequently 3GD4 and 1B48 in complex with its ligands were retrieved from the Protein Data Bank (http://www.rscb.org/pdb) ${ }^{18,19}$. The water molecules, complexes, and heteroatoms bound to the receptor molecules were removed from each protein structure. Finally hydrogen atoms were merged to the target receptor molecules. Protein preparation have done using AutoDockVina software. ${ }^{20}$ Ligands used in this study, they are Flavin Adenine Dinucleotida (FAD), Nicotinamide Adenine Dinucleotide (NADH), Nicotinamide Adenine Dinucleotide Phospate (NADPH), 2-methyl-1,4-naphthoquinone (menadione), reduced gluthatione (GSH), and menadione-S-gluthatione (thiodione). Ligands were sketched using Marvin Sketch software. Dreiding energy lowest was built to optimize all ligands using Marvin Sketch.

\section{Superposition and active site analysis.}

3D structure alignment of AIF and GST was employed in order to know the folding similarity of both protein, especially on transferase binding domain. This analysis was performed by FATCAT structural alignment ${ }^{21}$. Alignment result become a standard to create grid boxes for investigating transferase domain on AIF. This domain used as target domain of menadione binding. Then, interaction analysis was applied to find contact residues of menadione on AIF. Then, transferase residues of GST used as standard for finding the transferase catalytic site of menadione binding on AIF.

\section{Docking studies using AutoDockVina.}

The docking analysis of AIF with ligands was carried out by AutoDockVina docking software which is most commonly available software. Grid resolution was set to $1 \AA$, located to FAD or NADH binding domain. Superposition of 3D structure of AIF and GST was studied in order to know the folding similarity of both protein, especially on transferase binding domain. This analysis was performed by FATCAT structural alignment. ${ }^{21}$ Affinity energy indicated the easy binding of ligand and receptor.

\section{Interaction receptor-ligand analysis.}

Interaction between docked ligand and its receptor analyzed by AutoDockVina software Energy analysis of AIF with ligands was carried out by AutoDock tools. Parameters that measured are a number of close residues, hydrogen bond, and the distance between functional groups of ligand and close residues of 
receptor. Further analysis was applied to investigate the suitability of functional group and residues in order to measure the type of other interaction.

\section{Results and Discussion}

\section{Investigation transferase catalytic site of AIF.}

Generally, arylation between quinone and antioxidant in the cells is associated with Gluthatione-STransferase (GST). GST facilitates the conjugation of GSH to xenobiotic substrates to form gluthatione-Sxenobiotic-conjugate for detoxification purpose. Base on this fact and previous result that showed the contribution of AIF in menadione-GSH arylation, this part focus on the investigation of transferase catalytic site of AIF (compared to GST). Structural alignment of AIF and GST (as a template), was applied using FATCAT flexible program, which aligned AIF and GST database. The alignment result showed that transferase domain of GST was aligned to N-terminal and FAD domain of AIF (excluding the NADH domain residues). When AIF was aligned to GST, AIF has only $5.6 \%$ identity and $13.43 \%$ similarity transferase residues of GST (Figure 1).

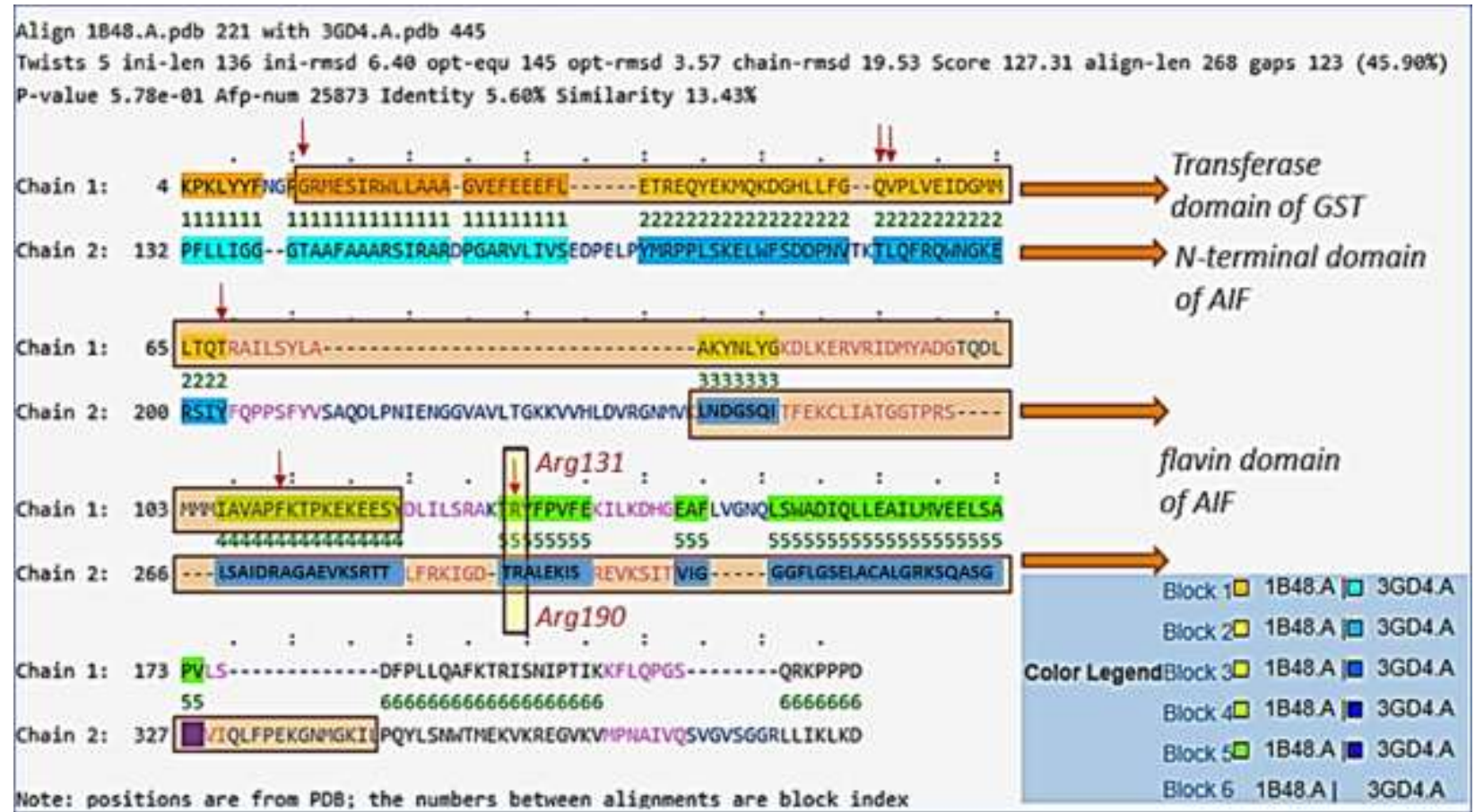

Figure 1. Structure alignment of AIF and GST. Red arrow indicate transferase contact residues of GST. Yellow box indicate identity residues of AIF and GST. 


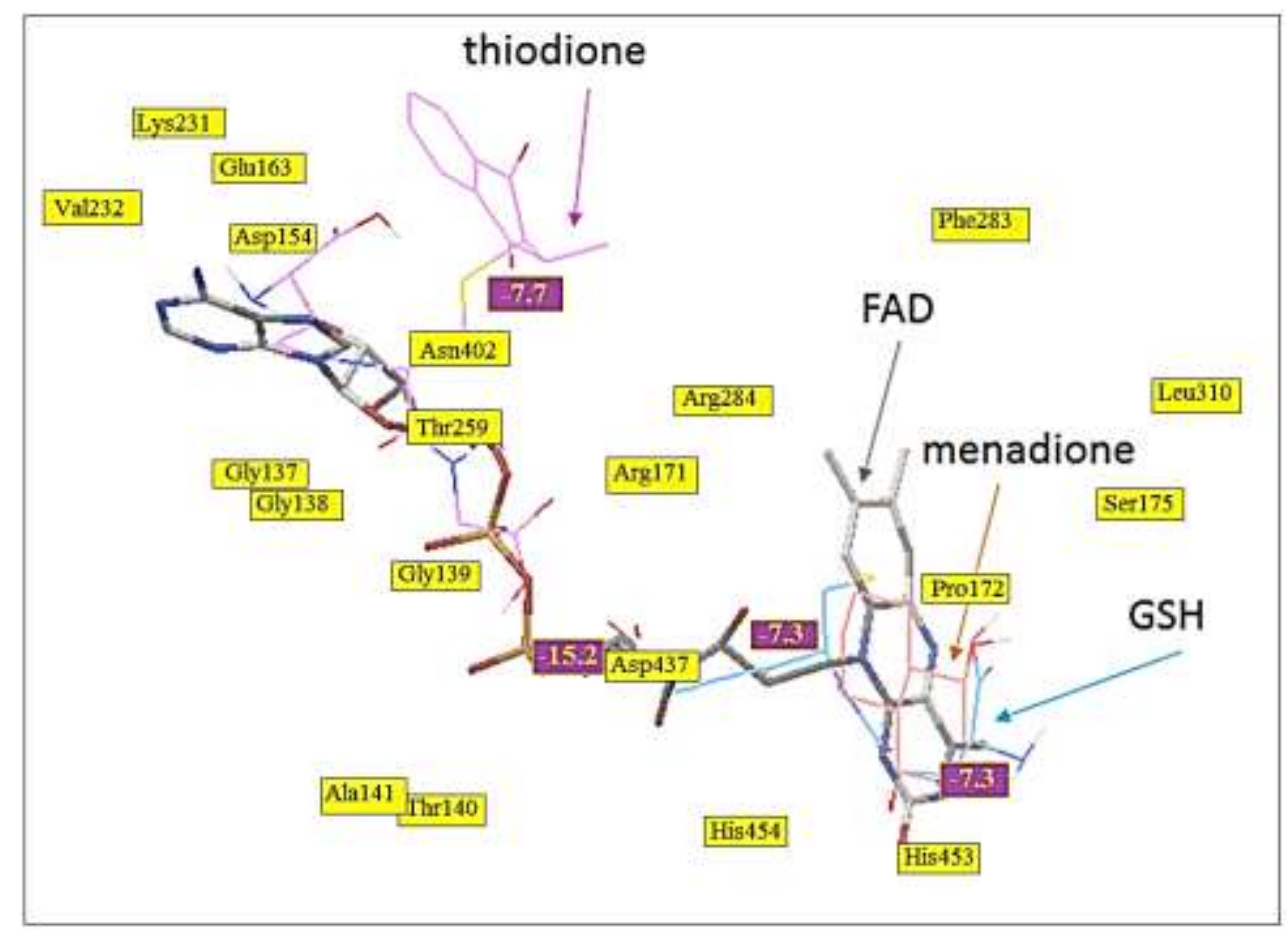

Figure 3. The position of ligands relative to FAD on FAD binding domain of AIF

Further investigation address to transferase catalytic site of GST aligned to AIF. Figure 1 showed transferase residues of GST are Gly14, Gln54, Val55, Thr68, Phe111, and Arg13. Among of them, AIF has only one identical residue; Arg190 which corresponds to Arg131 of GST. Moreover, further analysis showed that Arg190 does not belong to recognize residues of menadione or GSH binding to AIF (Figure 3).

\section{Binding Energy Analysis of menadione or GSH on FAD Domain of AIF.}

After approving that AIF does not have transferase residues, further investigation was performed in order to investigate other mechanism of AIF to modulate menadionearylation. As mention above that arylation capacity of menadione involving thiol proteins, computational study was applied to determine the affinity of arylation precursors; menadione or GSH to AIF. Given that in the modulation menadione cytotoxicity AIF does not use its nuclease activity (associated with C-terminal domain of AIF) and during that time AIF stay inside mitochondria (associated with N-terminal domain) ${ }^{11}$, computational approach focus on FAD and NADH domain of AIF. The result showed that affinity energy of AIF-menadione on NADH domain $-6.9 \mathrm{kcal} / \mathrm{mol}$, it is higher than AIF-menadione on FAD domain that showed $-7.3 \mathrm{kcal} / \mathrm{mol}$. The same phenomenon was shown by AIF-GSH, -6.3 kcal/mol on NADH domain compare to $-7.3 \mathrm{kcal} / \mathrm{mol}$ on FAD domain of AIF. Further investigation on arylation product of menadione-GSH showed that AIF-thiodione $-7.0 \mathrm{kcal} / \mathrm{mol}$ on NADH domain compare to $-7.7 \mathrm{kcal} / \mathrm{mol}$ on FAD domain of AIF. These results showed that arylation precursors or its product has better affinity to FAD compare to NADH domain (Table 2). Meaning, the tendency of AIF to use its NADH domain is lower than FAD domain, in presence of menadione or GSH.

Table 2. Affinity energy of ligands to NADH or FAD binding domain of AIF

\begin{tabular}{|l|c|c|c|}
\hline Ligands & $\begin{array}{c}\text { Affinity energy on NADH } \\
\text { binding domain } \\
\text { (kcal/mol) }\end{array}$ & $\begin{array}{c}\text { Affinity energy on FAD } \\
\text { binding domain } \\
\text { (kcal/mol) }\end{array}$ & $\begin{array}{c}\text { Ligand Stability to FAD } \\
\text { on FAD domain (\%) }\end{array}$ \\
\hline Menadione & -6.9 & -7.3 & 48 \\
\hline GSH & -6.3 & -7.3 & 48 \\
\hline Thiodione & -7.0 & -7.7 & 51 \\
\hline FAD & n.d & -15.2 & 100 \\
\hline NADH & -9.3 & n.d & n.d \\
\hline
\end{tabular}

Note : .d (not determined) 
Hesti L. Wiraswati et al/International Journal of PharmTech Research, 2017,10(4): 237-245.

Table 3. Strenght binding of ligands to residues on FAD binding domain of AIF

\begin{tabular}{|l|c|c|}
\hline $\begin{array}{c}\text { Ligands/number of interaction on } \\
\text { ligand binding }\end{array}$ & $\begin{array}{c}\text { Number of hydrogen } \\
\text { bonds }\end{array}$ & $\begin{array}{c}\text { Number of Van der Waals } \\
\text { interactions }\end{array}$ \\
\hline Menadione & 1 & 5 \\
\hline GSH & 3 & 4 \\
\hline Thiodione & 2 & 11 \\
\hline
\end{tabular}

\section{Binding Energy Analysis of Thiodione to AIF}

After confirming the lethal function of AIF on menadionearylation, further investigation was employed to understand the mechanism of AIF to modulate menadionearylation. Menadione, GSH, and thiodione were docked to AIF on FAD domain. The result showed that thiodione has better affinity to AIF compare to menadione or GSH (Table 2). Energy affinity showed $-7.3 \mathrm{kcal} / \mathrm{mol}$ on AIF-menadione (or AIF-GSH) interaction, compared to $-7.7 \mathrm{kcal} / \mathrm{mol}$ on AIF-thiodione interaction. The number of Van der Waals interaction 11 on AIF-thiodione compare to 5 on AIF-menadione or 4 on AIF-GSH (Table 3). Then, interaction analysis of ligand-receptor showed that thiodione was recognized by 13 residues of AIF (compare to menadione with 7 residues or GSH with 10 residues of AIF) (Figure 2). These results indicated that AIF-thiodione binding more stable compare to AIF-menadione or AIF-GSH.

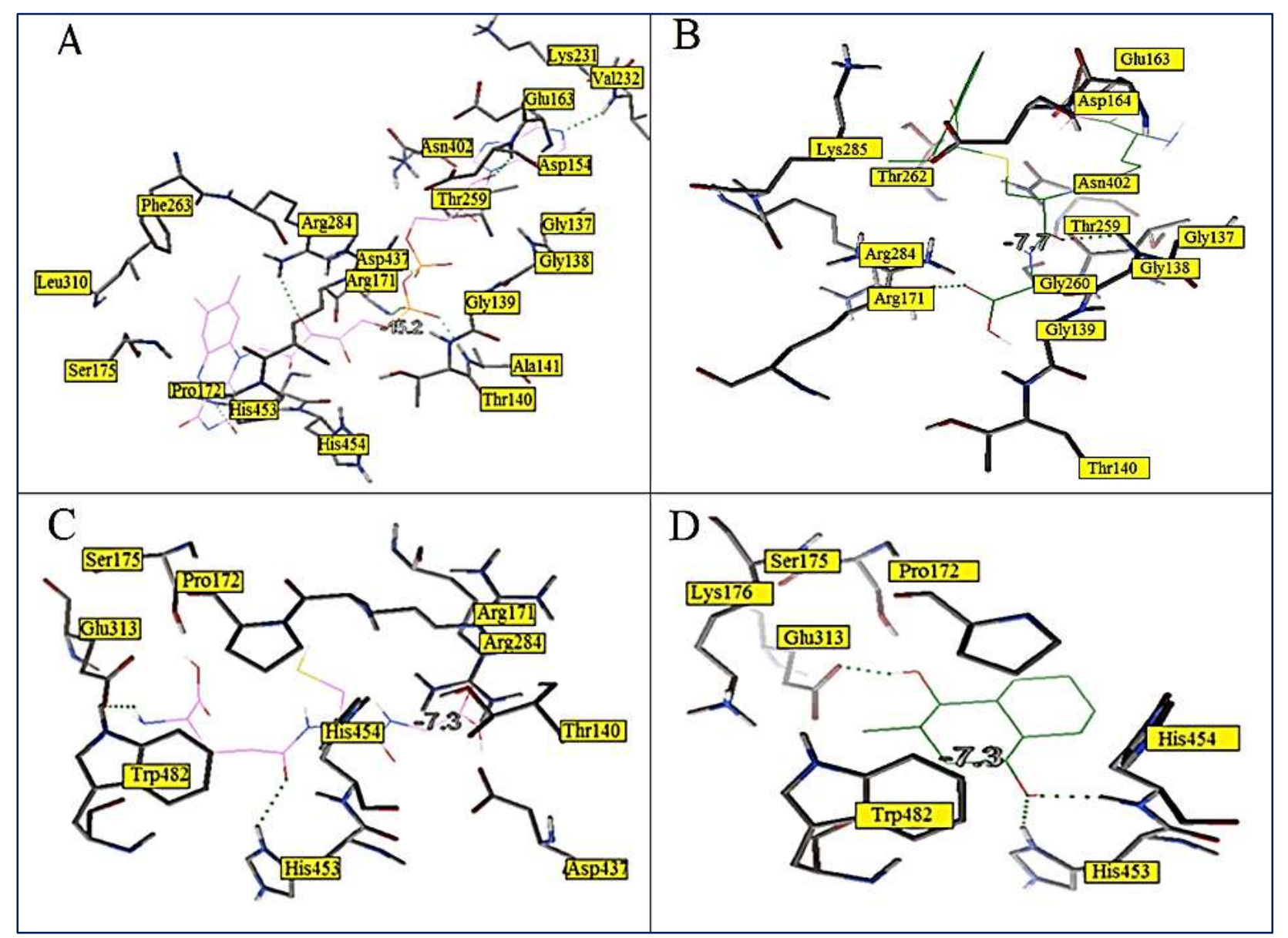

Figure 2. Contact residues of ligands on FAD binding domain of AIF. AIF-FAD (A). AIF-thiodione (B). AIF-GSH (C). AIF-Menadione (D). 
Further investigation was applied in order to understand interaction model of thiodione by AIF. Given that AIF-thiodione interaction located on FAD domain, binding affinity of original ligand of AIF must be investigated. Docking study was applied and the result showed that affinity energy of AIF-FAD $-15.2 \mathrm{kcal} / \mathrm{mol}$ compare to $-7.7 \mathrm{kcal} / \mathrm{mol}$ of AIF-thiodione (Table 2). Interaction analysis showed that FAD was held by 20 contact residues of AIF compared to 13, 10, or 7 contact residues on thiodione, GSH, or menadione respectively (Figure 2). Binding position of each ligands to AIF showed that more than half of thiodione structure is not in frame of FAD position, even being outside the AIF (Figure 3). Meanwhile the structure of menadione and GSH in frame of FAD position and were buried inside FAD domain of AIF (Figure 4).
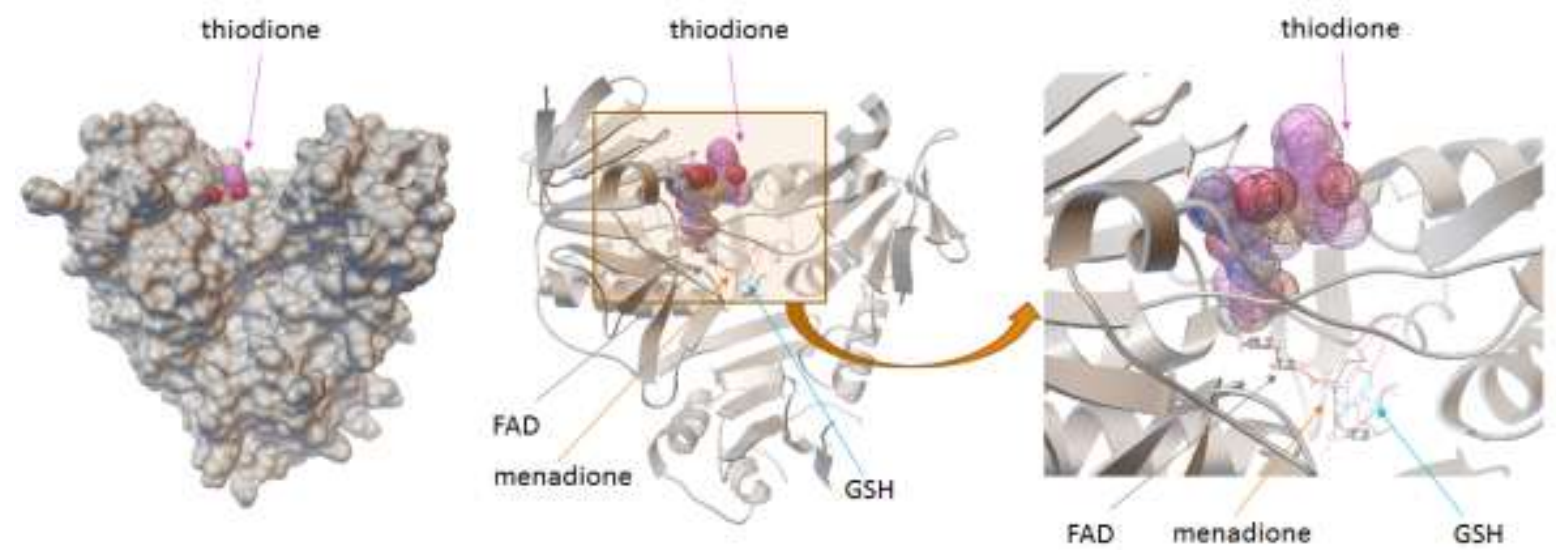

Figure 4. Molecular surface analysis of AIF. AIF was prepared as receptor that contain FAD. Ligands were docked to AIF on FAD binding domain. All docked ligands were positioned to FAD structure on FAD binding domain of AIF.

\section{Discussion}

Structural alignment result of AIF and GST that revealed AIF has only 5.6\% identity and $13.43 \%$ similarity transferase residues of GST, suggests that AIF has a weak tendency to act as transferase. Further investigation on transferase catalytic site also showed that AIF has only one identical residue (Arg190) from six transferase residues of GST, even Arg190 does not belong to recognize residues of menadione or GSH binding to AIF, it indicated that AIF does not have transferase catalytic site.

After approving that AIF does not have transferase residues, docking study showed that the tendency of AIF to use its NADH domain is lower than FAD domain in presence of menadione or GSH. As quinonereductase, AIF-menadione interaction supposed to be on NADH domain of AIF. This situation revealed that AIF tends to modulate arylation capacity of menadione and GSH rather than acts as NADH:quinonereductase. It confirmed that the lethal action of AIF is not related to its oxidoreductase activity $^{8,10,11,14}$. Further investigation on AIF-thiodione revealed that AIF tends to interact with thiodione compare to menadione or GSH. These results in agreement with previous report that revealed the lethal action of AIF induced thiodione formation in menadione-induced death of U2OS cells ${ }^{11}$.

It's been proved that FAD is crusial ligand for AIF to stabilize its structure ${ }^{18,22}$. This fact supported by in silico study that showed FAD has stability $200 \%$ higher compare to thiodione. It suggests that interruption of ligands to replace FAD on FAD domain is almost impossible. Although the number of contact residues that surrounds thiodione is $45 \%$ higher compare to menadione or GSH, more than half of thiodione structure is not in frame of FAD position, even being outside the AIF. Meanwhile the structure of menadione and GSH is in frame of FAD position and were buried inside FAD domain of AIF. These results also revealed that in condition thiodione bound to AIF, FAD still attached to FAD domain of AIF. All results reinforce the notion that in presence of FAD, AIF stabilizes thiodione formation rather than direct interaction to menadione or GSH. In conclusion, AIF is involved in the modulation of menadionearylation, specifically AIF stabilizes conjugate product-thiodione. 


\section{Conclusions}

Molecular interaction between residues on AIF and functional groups of menadione confirmed that AIF was involved in the conjugation of menadione and GSH to form thiodione. Moreover, in condition that AIF aligned to GST, AIF doesn't have transferase catalytic site which also confirmed that NADH is not required in the lethal action of AIF induced by menadione. ${ }^{11}$ Further investigation showed that AIF stabilizes thiodione formation rather than interact directly with menadione or GSH, in the modulation menadione metabolism.

\section{Acknowledgment}

The authors would like to humbly acknowledge the Higher Education Commission of Indonesia (DIKTI) and West Java provincial government for financial support during the research. Eventually, I would like to express my deep gratitude to GUIDO's lab (Institut Gustave Roussy, IGR-France) and Université Paris Sud-France.

\section{References}

1. M. Tetef, K. Margolin, C. Ahn, S. Akman, W. Chow, L. Leong, R.J.J. Morgan Jr., J. Raschko, G.D.J.H. Somlo and J.H. Doroshow, Invest. New Drugs, 13, 157 (1995); doi:10.1007/BF00872865.

2. I. Laux and A. Nel, Clin. Immunol., 101, 335 (2001); doi:10.1006/clim.2001.5129.

3. S. Matzno, Y. Yamaguchi, T. Akiyoshi, T. Nakabayashi and K. Matsuyama, Biol. Pharm. Bull., 31, 1270 (2008); doi:10.1248/bpb.31.1270.

4. D. Di Monte, D. Ross, G. Bellomo, L. Eklow and S. Orrenius, Arch. Biochem. Biophys., 235, 334 (1984); doi:10.1016/0003-9861(84)90206-6.

5. X. Wang, B. Thomas, R. Sachdeva, L. Arterburn, L. Frye, P.G. Hatcher, D.G. Cornwell and J. Ma, Proc. Natl. Acad. Sci. USA, 103, 3604 (2006); doi:10.1073/pnas.0510962103.

6. G.K. Scott, C. Atsriku, P. Kaminker, J. Held, B. Gibson, M.A. Baldwin and C.C. Benz, Mol. Pharmacol., 68, 606 (2005).

7. A.J. Mauzeroll, J. Bard, O. Owhadian and T.J. Monks, Proc. Natl. Acad. Sci. USA, 101, 17582 (2004); doi:10.1073/pnas.0407613101.

8. S.A. Susin, H.K. Lorenzo, N. Zamzami, I. Marzo, B.E. Snow, G.M. Brothers, J. Mangion, E. Jacotot, P. Costantini, M. Loeffler, N. Larochette, D.R. Goodlett, R. Aebersold, D.P. Siderovski, J.M. Penninger and G. Kroemer, Nature, 397, 441 (1999); doi:10.1038/17135.

9. L. Miseviciene, Z. Anusevicius, J. Šarlauskas, I.F. Sevrioukova and N. Čènas, Arch. Biochem. Biophys., 512, 183 (2011); doi:10.1016/j.abb.2011.05.015.

10. E.K. Hangen, K. Blomgren, P. Benit, G. Kroemer and N. Modjtahedi, Trends Biochem. Sci., 35, 278 (2010); doi:10.1016/j.tibs.2009.12.008.

11. Wiraswati, H. L.; Hangen, E.; Sanz, A. B.; Lam, N. V.; Reinhardt, C.; Sauvat, A.; Mogha, A.; Ortiz, A.; Kroemer G.; Modjtahedi, N., Oncotarget., 22, 76496 (2016).

12. J.P. Monteiro, A.E. Martins, C. Nunes, C.M. Morais, M. Lucio, S. Reis, T.J. Pinheiro, C.F. Geraldes, P.J. Oliveira and A.S. Jurado, Biochimia et Biophysica Acta, 1899 (2013).

13. C.A. Koczor, I.N. Shokolenko, A.K. Boyd, S.P. Balk, G.L. Wilson and S.P. Ledoux, J. Biol. Chem., 284, 36191 (2009); doi:10.1074/jbc.M109.036020.

14. M.J. Mate, M. Ortiz-Lombardia, B. Boitel, A. Haouz, D. Tello, S.A. Susin, J. Penninger, G. Kroemer and P.M. Alzari, Nature Struct. Biol., 9, 442 (2002).

15. M.D. Miramar, P. Costantini, L. Ravagnan, L.M. Saraiva, D. Haouzi, G. Brothers, J.M. Penninger, M.L. Peleato, G. Kroemer and S.A. Susin, J. Biol. Chem., 276, 16391 (2001); doi:10.1074/jbc.M010498200. 
16. N. Joza, S. Susin, E. Daugas, W. Stanford, S. Cho, C. Li, T. Sasaki, A. Elia, H. Cheng, L. Ravagnan, K. Ferri, N. Zamzami, A. Wakeham, R. Hakem, H. Yoshida, Y. Kong, T. Mak, J. Zúñiga-Pflücker, G. Kroemer and J. Penninger, Nature, 410, 549 (2001); doi:10.1038/35069004.

17. H. Otera, S. Ohsakaya, Z. Nagaura, N. Ishihara and K. Mihara, EMBO J., 24, 1375 (2005); doi:10.1038/sj.emboj.7600614.

18. I.F. Sevrioukova, J. Mol. Biol., 390, 924 (2009); doi:10.1016/j.jmb.2009.05.013.

19. B. Xiao, S.P. Singh, B. Nanduri, Y.C. Awasthi, P. Zimniak and X. Ji, Biochemistry, 38, 11887 (1999); doi:10.1021/bi990468i.

20. O. Trott and A.J. Olson, J. Comput. Chem., 31, 455 (2010); doi:10.1002/jcc.21334.

21. Y. Ye and A. Godzik, Bioinformatics, 19, 246 (2003).

22. G.L. Kroemer, L. Galluzzi and C. Brenner, Physiol. Rev., 87, 99 (2007); doi:10.1152/physrev.00013.2006. 